\title{
Conceptual Framework for Banking Solutions based on Real Time Marketing
}

\author{
P. C. Jha \\ Department of \\ Operational Research \\ University of Delhi Delhi, \\ India
}

\author{
Remica Aggarwal \\ MIT - School of \\ Education \& Research, \\ MIT-ADT \\ University Pune, India
}

\author{
U. Dinesh Kumar \\ IIM Bangalore \\ Bangalore, India
}

\author{
Gayathri S. \\ ICICI Bank \\ Bannerghatta Road, \\ Bangalore
}

\begin{abstract}
In today's competitive environment, marketing is critical to business success across all sectors. The challenge is even more pronounced in the financial sector and in order to survive and thrive in the financial crisis, it is required that these institutions should go for a revolutionized style of marketing known as real time marketing which involves conducting more focused inbound marketing campaigns and promoting the products to appropriate segments, at the right time and in the right place. The present research explores how financial institutions such as banks respond to real time marketing and the kind of inbound real time marketing offers by them which are usually governed by criteria such as income generation, age, family size etc.
\end{abstract}

\section{Keywords}

Marketing, Real time marketing, Inbound marketing , Analytics , Predictive modeling

\section{INTRODUCTION}

In recent years marketing is revolutionized as real time or inbound marketing that seeks the most appropriate offer for a given customer sales opportunity against the traditional outbound marketing (or interruption marketing) which aims to acquire appropriate customers for a given 'pre-defined' offer . Such a revolutionized marketing happens at the moments when a consumer shows interest on a company through inbound channels such as ATM, website, on the phone, a Facebook page, or in store, and continues the conversation in outbound channels like email, SMS and direct mail. In addition to technological innovation and globalization, other forces also drive the redesign of business strategies, for example, the deregulation and privatization occurring in various economies [1]. Therefore, organizations should be constantly updated with real time market information to ensure that they can receive, analyze and act on a flow of information that describes dynamically the market environment and its internal operations [2].

The main challenge with inbound real time marketing is to choose the best offer for each of the customer when he/she interacts with organization. As each customer is different in their profiles, they should warrant different personalized actions when interacted with organization, the one which is most beneficial for them. This becomes even trickier when there are thousands of offers to choose from. There is also the possibility that the best offer/ action for an individual may not be the best profitable action for the organization in terms of revenue or sales targets or effective use of available resources. This requires a multi-dimensional tradeoff between the customer's preferences and the firm's profit maximization goals under budget, sales target, capacity constraints and ROI expectations [3].

Different analytics companies works differently in determining the best action or offer while doing real time marketing. This requires combining the timely and accurate information with predictive analytics. For example, IBM works with four different approaches viz. experience, automation, rule management and recommendation engine [4] . Similarly, Neolane's works with four different approaches as cross-channel offer catalogue, personalized experiences, easy to manage business rules and full marketing control [5]. Similarly ADOBE's real time interaction management works with approaches of centralized offer engine, marketing friendly business rules and integrated customer's profiles [6]. Genpact offers products and services enabled by Genpact Cora - an artificial intelligence (AI)-based platform [7] to reframe and solve real world business issues to drive digital transformation across the banking and financial services industry.

\section{REAL TIME MARKETING IN BANKING SECTOR}

The real time marketing challenge is even more pronounced in the financial sector due to the mistrust of the capacity of financial institutions in the current economic environment. In banking sector, the most used inbound channel options are ATM's, internet, mobile banking and phone calls. The range of products offered through these channels being typical banking products which include savings or current bank account, family wealth accounts, home loans, car loans, education loans , foreign exchange services, lockers and DMAT accounts . Then, there are privilege products include credit cards, debit cards, insurance, investments, mortgage and value added services.

Following section discusses real time banking options, suggested options and the guiding criteria behind them

\subsection{ATM's}

The real-time alerts, which range from suspicious activity being detected to cash being withdrawn from an ATM are sent via SMS text message, email or both. Cardholders may also receive real-time alerts for international transactions, gasoline purchases, ATM withdrawals, declined transactions or for online, mail-order or telephone transactions where the card is not present [8].

\subsection{Internet and social media}

Customers are using the platform of internet and social media to actively spread the word in real time about their customerservice experiences. The average facebook user has 100 friends who can find out about a bad banking experience within seconds and well-treated customers are becoming 
unofficial spokespeople for certain brands.

\subsection{Mobile banking}

Usually banks divide their customers to different segments so as to catch up with their requirements which can be timely fulfilled so as to optimize customer retention, acquisition and advance. Following are the various categories of mobile banking consumers :

$>$ Aspiring bloomers: This segment is digitally inclined but not among the first to adopt mobile banking. However, they access mobile banking services at least once a week. Mobile banking features such as checking account balances, transferring funds and remote payments are important. Consumers in this segment are willing to try and adopt advanced features such as mobile photo bill pay, virtual wallet services and near-field communication payments. These customers can be targeted about advanced bank features such as mobile photo bill pay and NFC through direct marketing campaigns.

$>$ Ardent affluents: This segment is highly engaged with their mobile devices. They use advanced features such as mobile photo bill pay, and are interested in receiving expert guidance on personal finance and investments. They seek value-added services such as spending pattern analysis, loyalty rewards/points. This is an ideal market segment for the introduction of digital wallet offerings that drive revenue through offers and payments and increase engagements and loyalty. Remote deposit capture (RDC) is the feature most desired by aspiring bloomers and ardent affluents.

> Liberal users: This segment consists of consumers between the ages of 35 and 54. They use mobile banking, but not extensively. They also seek advice to help them improve how they manage their finances. This segment will respond best to services related to money management.

$>$ Cautious seniors : These consumers are value seekers. They are interested in products that offer tangible rewards. This segment is also highly sensitive to mobile security concerns. Real-time alerts on unusual account activity is the feature most desired by liberal users and cautious seniors - reinforcing that security is a critical concern to these segments in further adopting mobile banking services

$>$ Disinclined conservatives: This segment has serious concerns about the safety and security of mobile transactions. Currently available banking services meet their existing needs. Retail banks can gain from informing them about the benefits of mobile banking and alleviating their security concerns.

\subsection{Inbound calls}

Through inbound calls, banks can target different age groups customers and offer them a variety of financial services after considering the consumer financial planning cycle [8]. For example, single adults who just enter college can be encouraged to go for auto loans, credit cards and debit cards. On the other hand, childless couples are encouraged for joint checking accounts, CD's etc., young families are floated with offers such as home mortgage, loans, insurance, education loans. Mature adults are offered, mortgage, estate planning and retirement plan.

\subsection{Geo referenced advertising}

Geo-referenced advertising can be addressed through decomposition, study and optimization of the following three tasks independently: (i) determining the geographical scope of web pages, (ii) classifying web pages according to their geographical interest, and (iii) determining which ads are most relevant to a given page. Banking sector can also benefit from geo-referenced advertising. Bank web pages can be tailored to different geographical interest and in fact geographical information can be applied to all channels of contact.

\subsection{Retention offers during cancellation}

Leading retail banks are now positioning themselves for the recovery of their lost accounts by staying connected with customers, even those who have stopped buying or have deferred major purchases. Various retention offers can be offered based on the nature of termination. For example, when the customer contact the organization to cancel their agreement, these banks pose a retention offer appropriate to the reason for cancellation. Similarly, when a customer contact and is close to the end of their current agreement, organization representative discusses a proactive retention offer.

\section{TECHNIQUES OR SOLUTIONS TO REAL TIME MARKETING}

Different techniques or innovations have been suggested to provide a solution to above mentioned problem. For example, the quite popular real time offer optimization by WIPRO [9] which leverages real-time customer behavior including the latest transactions and social feeds, individualized demographics, and dynamic pricing and merchandising to recommend products and offers. The inbuilt algorithms and business rules match customers' unique interests to relevant promotions and digitally deliver instant and automatic results. Another important innovation is omni channel delivery models. They enable employees and users to seamlessly interact with bank systems through cloud, mobile, Web, text and other preferred channels. Then there is in-memory computing platform called SAP HANA which is built to store and analyze big data from multiple systems. It helps banks achieve a more comprehensive and instant view of their customers and business performance. The solution from SAP consists of an integrated business intelligence platform, agile data visualization by SAP Lumira and the ability to leverage sophisticated models and algorithms to predict customer behavior with SAP Predictive Analysis [10].

\section{PROBLEM STATEMENT}

The problem under consideration deals with offering multiple financial offers to a set of customers over a definite time period let us say month or year through multiple channels . Channels may include inbound channels as discussed before like ATM , inbound calls, offline channels such as TV, Radio , print or online channels such a paid search , email, display, affiliates or non- paid search . Focus of the present study is on the broad channels that bank communicate through i.e. ATM, inbound calls, telephone, social media websites and bank website. Product offers includes savings or current bank account, family wealth accounts, home loans , car loans , education loans, foreign exchange services , lockers , DMAT accounts, credit cards , debit cards , insurance, investments, mortgage, value added services etc. 


\section{Problem scenario}

Each customer may be contacted for different products in different time periods through a different channel. For example, let us say product P1 offered to customer 1 . So basically each customer is offered a product over a set of elements in each time period. It could be like a product P1, an insurance policy which is offered to customer 1 (with respect to a criteria let us say age 30-40 years) in the first week of July 2018 through an inbound call, the offer is a 10\% discount on the first installment. Here the elements are product $\mathrm{P} 1$, the offer and the time period which is first week of July. Similarly in the second week another offer is presented through ATM display which is a discount of $5 \%$ on cash purchase of the bonds. Similarly, in third and fourth week respectively. At the end of the month a sale is generated from that customer. Also, there is a likelihood given to us i.e. total likelihood that a person in a certain criteria (a certain age group 30-40 years here) will make a purchase this month. Now for the second customer, may be the offers are given at the same time period as the first customer or different time periods (let us say after 2-3 days) in that month. The problem is many folds i.e.

- To find the likelihood for each customer corresponding to each product in each time period.

- To diagnose as to what combination of the four elements (i.e. product, offer, channels, and time interval ) can contribute to the overall sales.

\section{MODEL FRAMEWORK DEVELOPMENT}

This section describes a general framework for real time offers that a bank can offered to its set of customers (potential customers) over different time intervals within a specified period through different channels. The framework is developed to find out individual likelihood for each element in each time period (this could be week or days) so that the sales generated at the end of the period can be maximized. At the same time, it can be diagnosed as to what combination of the four elements (i.e. product, offer, channels, and time interval ) can contribute to the overall sales. The framework is developed under the following assumptions :

- Sale is to be made once and only once

- Single purchase per customer per period

- No repeat purchase

Following notations have been used in the model framework development.

\subsection{Notations}

$\mathrm{P}_{\mathrm{s}}$ : Product s $(s=1,2,3,4,5)$

NS: No Sale

SG: Sale generated

SP1: Sale generated for product P1

$i$ : customer $; i=1,2, \ldots .1000$

$t_{i j}$ : time period ; $j$ : week ; if $i=j$ for all $i, j$ we have homogenous time periods else if $i \neq j$, we have heterogeneous time periods

$\mathrm{k}$ : element $(\mathrm{k}=1,2,3,4) ; \mathrm{k}=1$ : product; $\mathrm{k}=2$ : offer; $\mathrm{k}=3$ : time ; $\mathrm{k}=4$ : channel

$\mathrm{L}_{k i j}$ : likelihood that an element ' $k$ ' is selected by customer ' $i$ ' in time period ' $j$ ' (week ' $j$ ' here; $0<\mathrm{L}_{\mathrm{ikij}}=$ likelihood of each customer $<=1$ )

To proceed with, first a customer elements matrix over the specified time period is constructed to give an idea as to how the flow of marketing takes place in generation of sales. Time intervals in which the product offer has been made, differ with respect to customer and product. For example, it may be possible that customer 1 is contacted the entire first week of July for product 1 . So in this case the time interval is one week for first product offer for customer 1. Table 5.3.1 presents a sample customer data for the sale made in the month of July 2018 for five different bank products, different offers over different time periods, through different channels. For the sake of simplicity five different products (P1, P2, P3, P4, P5) ; three inbound channels (ATM , CALL, WEBSITE) has been considered. We can create similar matrices corresponding to other criteria such as income, family size and marital status. We can further break up each of the last five columns of table 1 in multiple time periods in order to see in which period the sale is generated. However for simplicity as the sale generated is a single sale combining all the time period as one time period, the final sale generated is the sale generated in the month of July.

The present research explores the widespread concept of real time marketing and a financial institution response to it so as to restore its customers . The research paper also attempts to present a strategic framework to find the likelihood for the customer corresponding to the bank real time offer in each time period. Research however can be extended to include the optimization model to maximize the sales in multiple periods with multiple products .

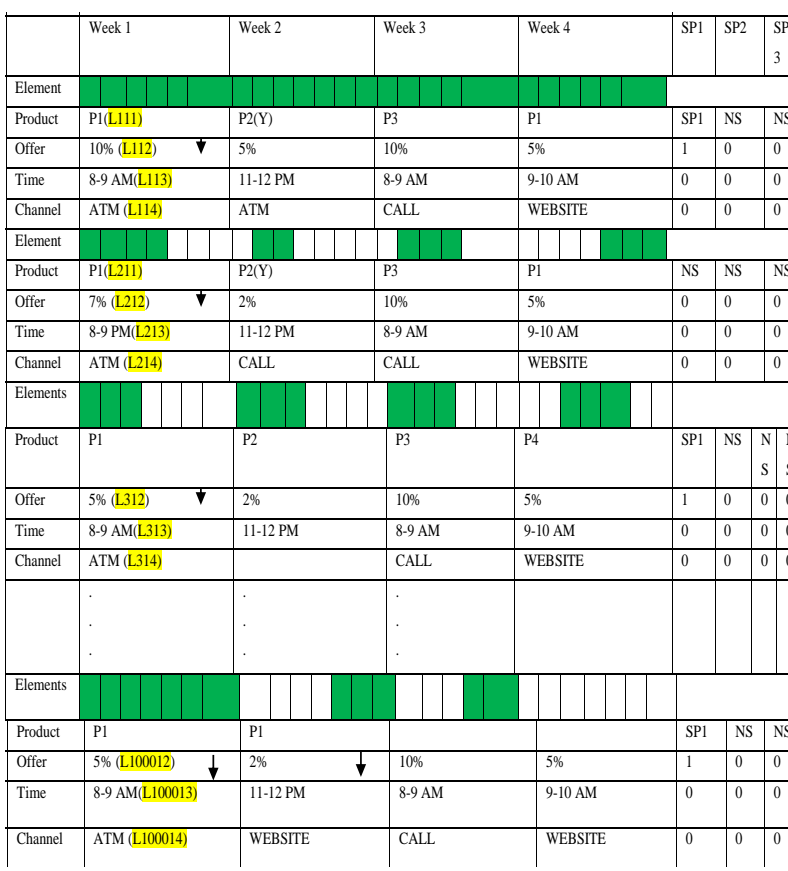

Figure 1 : Customer - elements matrix over different time periods w.r.t Age group (AG), Income (In), Marital status (MS), family status (FS), product (Pr), Offer (Of); Time (Ti); Channel (Ch); Date within month of (Jul 131 ${ }^{\text {st }}$ (Dt) 


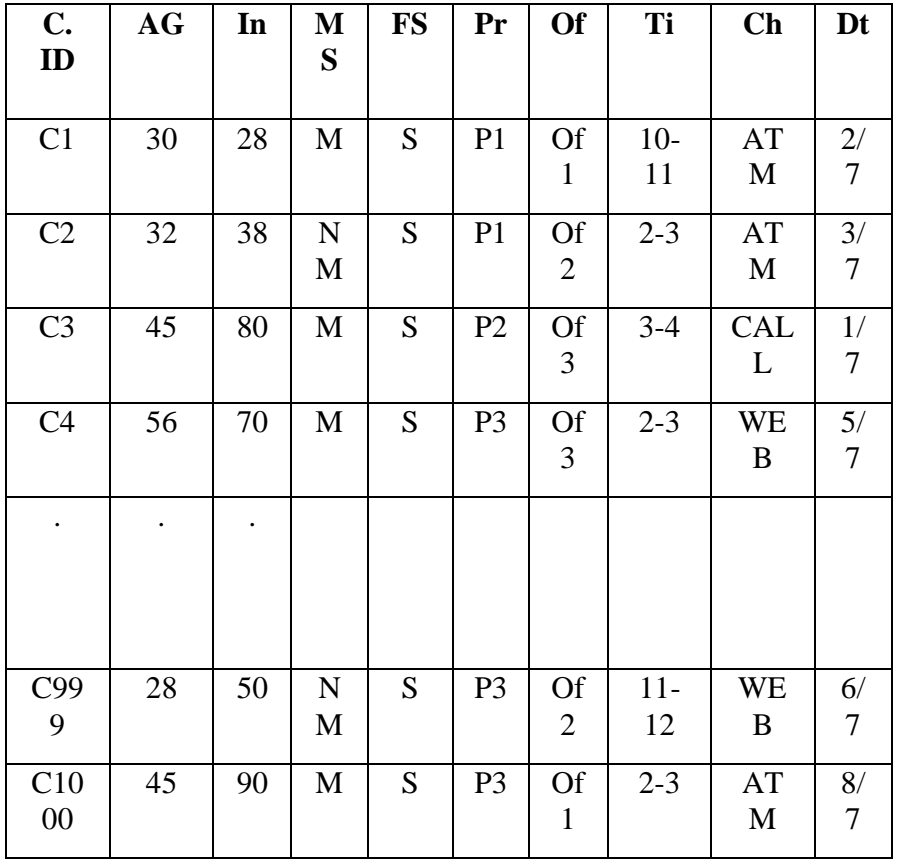

Figure 2 : Sample comprehensive data showing criteria, elements and customer ids together (hypothetical data of say 1000 customers). Income is in ' 000 INR

\section{CONCLUSIONS}

The present research explores the widespread concept of real time marketing and a financial institution response to it so as to restore its customers. The research paper also attempts to present a strategic framework to find the likelihood for the customer corresponding to the bank real time offer in each time period. Research however can be extended to include the optimization model to maximize the sales in multiple periods with multiple products .

\section{ACKNOWLEDGMENTS}

Author Remica Aggarwal pays her sincere regards to Shri V. Prasad from Genpact, Bangalore for the knowledge sharing over the concept .

\section{REFERENCES}

[1] Kotler, P. and Armstrong, G. 2009. Principles of Marketing (13 ${ }^{\text {th }}$ Edition). Prentice Hall. pp. 49-54. ISBN: 0136079415 .

[2] Panian, Z. 2007. Just-in-Time Business Intelligence and Real-Time Decisioning. International Journal of applied Mathematics and Informatics. 1(1), 28-35.

[3] britain.experian.com/www/pages/what.../real_time_mark eting.htm

[4] http://www-01.ibm.com/software/in/marketingsolutions/real-time-marketing-solution/

[5] http://www.neolane.com/Assets/neolane.comAssets/usassets/resources/pdf/Neolane\%2520Interaction_DS_2013 .pdf

[6] http://wwwimages.adobe.com/content/dam/Adobe/en/sol utions/campaign/pdfs/solution-overview-neolaneinteraction-ue.pdf

[7] http://www.genpact.com/what-we-do/digital/digitalproducts-services/banking-capital-markets

[8] http://www.pwc.com/us/en/financialservices/publications/viewpoints/assets/viewpoint-retailbank-customer-centric-business-model.pdf

[9] http://www.wipro.com/industries/retail-solutions/realtime-offer-optimization.aspx

[10] http://www.sap.com/bin/sapcom/en_us/Banks\%20Bettin g\%20Big\%20on\%20Big\%20Data\%20and\%20RealTime\%20Customer\%20Insight\%20(Bloomberg\%202013 )-pdf.html 